\title{
Visual acuity assessment in phakic and pseudophakic eyes under red, green, and blue illumination
}

\section{Valoración de la agudeza visual con iluminación roja, verde y azul en ojos fáquicos y pseudofáquicos}

\author{
Laura Clavé1,2, $\mathrm{S}^{*}$, Aurora Torrents ${ }^{1}$, Miquel Ralló1, María S. Millán ${ }^{1, \mathrm{~S}}$ \\ 1. Grupo de Óptica Aplicada y Procesado de Imagen, Departamento de Óptica y Optometría, Universitat \\ Politècnica de Catalunya-BARCELONATECH, España \\ 2. Hospital de Mataró, Servicio de Oftalmología, Consorci Sanitari del Maresme \\ ${ }^{(*)}$ E-mail: lclave@csdm.cat \\ S: SEDOPTICA member
}

Received: 29/09/2020 Accepted: 10/11/2020

DOI: 10.7149/OPA.53.4.51047

\begin{abstract}
:
Purpose: To assess the impact of the quasi-monochromatic illumination on visual acuity (VA) in phakic and monofocal pseudophakic eyes using different wavelengths.

Methods: Sixty-one eyes classified in two groups (phakic and pseudophakic) participated in this study: 31 young phakic and 30 pseudophakic implanted with an acrylic monofocal intraocular lens. Distance VA was measured with custom optotype illuminated sequentially with three LED lights of nominal wavelengths (B) $455 \mathrm{~nm},(\mathrm{G}) 530 \mathrm{~nm},(\mathrm{R}) 625 \mathrm{~nm}$ and white (W) LED light (CCT=6500K). Near VA was additionally assessed in young phakic eyes under the same illuminations.

Results: Best mean distance VA was obtained under red and white lights in young phakic eyes, whereas it was obtained under white and green lights in pseudophakic eyes. For both groups, the blue illumination led to the worst mean distance VA outcomes. No significant differences were found among mean near VA for R, G an B lights, but it was significantly better under $\mathrm{W}$ light than under B light.

Conclusion: The measured distance VA values reveal the impact of the chromatic difference of refraction caused by the longitudinal chromatic aberration of the tested eyes. This aberration, is compensated by the accommodation capability of young phakics under red light. In the case of monofocal elderly pseudophakic eyes, a natural age-related decrease in the VA is observed. Additionally, the lack of accommodation, and a postoperative refraction outcome likely targeted for a green design wavelength, make the mean distance VA under green light match the one under white light. The mean near VA results in young phakic subjects revealed a balanced accommodation capability to every R, G, B illumination, but significantly higher under W light than under B light.
\end{abstract}

Key words: Accomodation, Color Vision, Pseudophakia, Vision Tests, Visual Acuity

\section{RESUMEN:}

Propósito: Valorar el impacto de la iluminación cuasi-monocromática en la agudeza visual (AV) en ojos fáquicos y pseudofáquicos utilizando diferentes longitudes de onda.

Método: El trabajo se realizó con 61 ojos clasificados en dos grupos: 31 fáquicos jóvenes y 30 pseudofáquicos implantados con una lente intraocular acrílica monofocal. La AV lejana fue medida usando un optotipo expresamente diseñado para el trabajo iluminándolo secuencialmente con tres luces LED de longitud de onda nominal de (B) $455 \mathrm{~nm}$, (G) $530 \mathrm{~nm}$, (R) $625 \mathrm{~nm}$ y blanca (W) (CCT= $6500 \mathrm{~K}$ ). Adicionalmente se midió la AV cercana usando las mismas iluminaciones en el grupo de jóvenes fáquicos. 
Resultados: La mejor AV lejana en ojos fáquicos se obtuvo con las iluminaciones roja y blanca mientras que en el grupo de pseudofáquicos ésta se obtuvo con las iluminaciones verde y blanca. La AV con iluminación azul fue la que obtuvo peores resultados en ambos grupos. No se encontraron diferencias estadísticamente significativas en la AV cercana para las iluminaciones $\mathrm{R}, \mathrm{G}$ y $\mathrm{B}$, pero fue significativamente mejor con iluminación W que con iluminación B.

Conclusión: Los valores de AV lejana revelan el impacto de la diferencia cromática de refración (CDRx) provocada por la aberración cromática longitudinal de los ojos evaluados. Con iluminación roja, la capacidad acomodativa de los ojos jóvenes fáquicos compensa la aberración. En ojos pseudofáquicos, se observa una disminución natural de la AV. En estos casos, además, la perdida de la acomodación y un resultado refractivo postoperatorio calculado para una longitud de onda de diseño verde, hacen que la AV obtenida con luz verde sea igual a la obtenida con luz blanca. La AV cercana media obtenida en ojos fáquicos jóvenes revela un equilibrio en la capacidad de acomodación con iluminación $R, G$ y $B$, si bien la AV cercana es significativamente superior con luz blanca que con luz azul.

\section{REFERENCES AND LINKS}

[1] L. N. Thibos, A. Bradley, X. X. Zhang, "Effect of ocular chromatic aberration on monocular visual performance," Optom Vis Sci 68, 599-607 (1991).

[2] P. A. Howarth, A. Bradley, "The longitudinal chromatic aberration of the human eye, and its correction," Vision Res 26, 361-366 (1986).

[] L. N. Thibos, A. Bradley, D. L. Still, X. Zhang, P. A. Howarth, "Theory and measurement of ocular chromatic aberration," Vision Res 30, 33-49 (1990).

[4] M. Vinas, C. Dorronsoro, D. Cortes, D. Pascual, S. Marcos, "Longitudinal chromatic aberration of the human eye in the visible and near infrared from wavefront sensing, double-pass and psychophysics," Biomed Opt Express 6, 948-962 (2015).

[] S. Marcos, S. A. Burns, E. Moreno-Barriuso, R. Navarro, "A new approach to the study of ocular chromatic aberrations," Vision Res 39, 4309-4323 (1999).

[6] D. A. Atchison, G. Smith, M.D. Waterworth "Theoretical effect of refractive error and accommodation on longitudinal chromatic aberration of the human eye," Optom Vis Sci 70, 716-722 (1993).

[7] R. Navarro, "The optical design of the human eye: a critical review," J Optom 2, 3-18 (2009).

[8] P. A. Howarth, X. X. Zhang, A. Bradley, D. L. Still, L. N. Thibos, "Does the chromatic aberration of the eye vary with age?" J Opt Soc Am A 5, 2087-2092 (1988).

[9] C. Ware, "Human axial chromatic aberration found not to decline with age," Graefes Arch Clin Exp Ophthalmol 218, 39-41 (1982).

[10] P. Cooper, P.L. Pease, "Longitudinal chromatic aberration of the human eye and wavelength in focus," Am J Optom Physiol Opt 65, 99-107 (1988).

[11] E. F. Fincham, "The accommodation reflex and its stimulus," Br J Ophthalmol 35, 381-393 (1951).

[12] P. B. Kruger, S. Mathews, K. R. Aggarwala, N. Sanchez, "Chromatic aberration and ocular focus: Fincham revisited," Vision Res 33, 1397-1411 (1993).

[13] K. Graef , F. Schaeffel, "Control of accommodation by longitudinal chromatic aberration and blue cones," J Vis 12, 1-12 (2012).

[14] D. A. Atchison, G. Smith, Optics of the human eye. Oxford, Butterworth-Heinemann, (2000).

[15] R. Navarro, "Letter to the editor (reply)," J Optom 2, 163-164 (2009).

[16] M. S. Millán, F. Vega, I. Ríos-López, "Polychromatic image performance of diffractive bifocal intraocular lenses: Longitudinal chromatic aberration and energy efficiency," Investig Ophthalmol Vis Sci 57, 2021-2028 (2016).

[17] G. Łabuz, G. U. Auffarth, A. Özen, T. Van den Berg, T. M. Yildirim, H.-S. Son, R. Khoramnia, "The effect of a spectral filter on visual quality in patients with an extended-depth-of-focus intraocular lens," Am J Ophthalmol 208, 56-63 (2019).

[18] T. Nagata, S. Kubota, I. Watanabe, S. Aoshima, "Chromatic aberration in pseudophakic eyes," (Japanese) Nippon Ganka Gakkai Zasshi 103, 237-242 (1999).

[19] D. Siedlecki, A. Jóźwik, M. Zając, A. Hill-Bator, A. Turno-Kręcicka, "In vivo longitudinal chromatic aberration of pseudophakic eyes," Optom Vis Sci 91, 240-246 (2014).

[20] P. Pérez-Merino, C. Dorronsoro, L. Llorente, S. Durán, I. Jiménez-Alfaro, S. Marcos, “In vivo chromatic aberration in eyes implanted with intraocular lenses," Investig Opthalmology Vis Sci 54, 2654-2661 (2013).

[21] M. S. Millán, F. Vega, F. Poyales, N. Garzón, “Clinical assessment of chromatic aberration in phakic and pseudophakic eyes using a simple autorefractor," Biomed Opt Express 10, 4168-4178 (2019). 
[22] B. Y. F. W. Campbell, R. W. Gubisch, "The effect of chromatic aberration on visual acuity," J Physiology 192, 345-358 (1967).

[23] R. B. Rabbetts, Bennett \& Rabbetts' clinical visual optics. $4^{\text {th }}$ edition, Edinburgh, Butterworth Heinemann, (2007).

[24] International Council of Ophthalmology, "Visual acuity measurement standard," (1984).

[25] ISO 8596:2017, International Organization for Standardization, "Ophthalmic optics - Visual acuity testing - Standard and clinical optotypes and their presentation," (2017).

[26] www.thorlabs.com.

[그] J. T. Holladay, T. C. Prager, “Mean visual acuity,” Am J Ophthalmol 111, 372-374 (1991).

[28] www.ajlsa.com.

[29] J. Sjöstrand, L. Laatikainen, H. Hirvelä, Z. Popovic, R. Jonsson, “The decline in visual acuity in elderly people with healthy eyes or eyes with early age-related maculopathy in two Scandinavian population samples," Acta Ophthalmol 89, 116-123 (2011).

[으] D. B. Elliot, K. C. H. Yang, D. Whitaker, "Visual acuity changes throughout adulthood in normal, healthy eyes: seeing beyond 6/6," Optom Vis Sci 72, 186-191 (1995).

[31] H.-D. Luo, G. Gazzard, Y. Liang, A. Shankar, D. T. H. Tan, S.-M. Saw, "Defining myopia using refractive error and uncorrected logMAR visual acuity from 1334 Singapore school children ages 7-9 years," Br J Ophthalmol 90, 362-366 (2006).

[32] T. C. Jenkins, “Aberrations of the eye and their effects on vision: 1. spherical aberration.," Br J Physiol Opt 20, 59-91 (1936).

[33] "11979-2. International Organization for Standardization. Ophthalmic implants, intraocular lenses part 2: Optical properties and test methods," (2014).

[34] P. B. Kruger, S. Nowbotsing, K. R. Aggarwala, S. Mathews, "Small amounts of chromatic aberration influence dynamic accommodation,” Optom Vis Sci 72, 656-66 (1995).

\section{Introduction}

Chromatic aberration of the human eye is produced by the dependence of the refractive index of the ocular media with the wavelength. In an optical system, longitudinal chromatic aberration (LCA) is determined from the chromatic difference in power, but in the human eye, it is estimated from the chromatic difference of refraction (CDRx)[1] corresponding to extreme wavelengths. Many studies have measured LCA in the human eye both experimentally and theoretically [2-6] and give very similar values of around 2D between 400 and 700 nm.[7] LCA is rather constant across population and with age.[8,9] These 2D focus difference between extreme colours of the visible spectrum causes the eye to behave, at far distances, as if it were myopic for short wavelengths and hypermetropic for long wavelengths.

The effect of accommodation on LCA of the eye has been described widely. Atchison et al.[6] used formulas based on reduced eyes to predict the variation of LCA with accommodation and showed an increment of LCA magnitude between $2.1 \%$ and $2.6 \%$ per diopter. Cooper et al.[10] measured LCA in 14 observers using a Badal optometer and did not find any difference between far and near LCA measurements, but the wavelength in focus was shorter at near distance.

The effect of LCA on accommodation has been investigated too. It has been shown that LCA provides a powerful and reliable directional cue for accommodation.[11-13]

Despite the rather high magnitude of LCA, its incidence in vision quality is attenuated by two mechanisms: the eye's lower sensitivity to light at both ends of the spectrum, for which the dioptric error is greater, [14] and the low density of short wavelength-sensitive cones, which is only about $1 / 10$ of the total cone mosaic.[15]

The replacement of the natural lens of the eye by an intraocular lens (IOL) might modify the LCA of the pseudophakic eye, depending on the chromatic dispersion of the lens material as well as other design features of the implant.[16] In general terms, the more dispersive the IOL material (lower Abbe number), the greater the LCA. This issue is of increasing interest today and has an influence on the new designs for presbyopia correcting IOLs.[17]

Several authors have studied the impact of different types of IOLs on the LCA of the eye. Nagata et al.[18] used a Bobier and Sivak chromoretinoscope to determine the refractive difference under illumination wavelengths of 500 and $640 \mathrm{~nm}$. They measured CDRx in forty implanted eyes with poly methylmethacrylate (PMMA) IOLs (Abbe value 58) and 49 eyes with soft acrylic (Acrysof) lenses (Abbe 
value 37) and determined that the eyes with implanted Acrysof lenses had a CDRx greater than eyes with PMMA (0.98D vs. 0.64D). Siedlecki et al.[19] measured the refraction with different wavelengths $(470,525$ and $660 \mathrm{~nm}$ ) and used a modified refractometer to assess the variation of the CDRx with the IOL material. Perez-Merino et al.[20] measured CDRx in implanted eyes with two types of acrylic lenses, Tecnis (Abbe value 55) and Acrysof (Abbe value 37) by ray tracing with two wavelengths (532 and $785 \mathrm{~nm}$ ) and reported a significantly lower CDRx value for Tecnis than for Acrysof. Millan et al.[21] found lower levels of CDRx in pseudophakic eyes implanted with three types of IOL than in phakic eyes using an autorefractor with a Scheiner disc illuminated with different wavelengths. Among the pseudophakic eyes, those implanted with IOL materials of higher Abbe number reported lower CDRx values.

Most studies report LCA data as CDRx, but as far as we know, the impact of LCA on the visual acuity (VA) has been scarcely studied. Campbell et al.[22] in 1967, showed that contrast sensitivity and VA improved when monochromatic $578 \mathrm{~nm}$ lighting and small pupils $(1.5$ and $2.5 \mathrm{~mm})$ were used. With larger pupils $(4 \mathrm{~mm})$, the results did not differ from those obtained with white light.

The aim of this research is to study the impact of quasi-monochromatic light on clinical VA assessment in young phakic and elderly pseudophakic eyes. For this purpose, we consider a simple method, which consists in lighting optotypes with quasi-monochromatic R,G,B lights for the clinical assessment of distance VA in all observers and near VA in only young phakic eyes. In the analysis of the measurements, possible correlations will be sought with the CDRx values reported in related studies concerning phakic and pseudophakic eyes. Other effects such as those possibly derived from accommodation or ageing will be considered and discussed.

\section{Material, method and observers}

\section{2.a. Material}

We used an optotype chart designed specifically for measuring VA in the study. The testing distance was $3.5 \mathrm{~m}$. The optotype consists of a high contrast black stimulus on a white background. Stimuli are presented in groups of five per line according to the Bailey and Lovie chart design; the space between stimuli corresponds to the size of one of them. From one line to another, the size of the stimuli follows a logarithmic progression, in steps of $0.1 \operatorname{logMAR}$. [23] The origin of the scale VA $(\log M A R)=0($ Snellen 6/6) corresponds to the normal visual resolution of 1 arc minute.

We chose Landolt rings as stimuli for the measurement of VA, in accordance to the recommendations of the Universal Ophthalmological council of 1984 and the guidelines set by the ISO 8596 standard.[24,25] The Landolt ring is the reference optotype for VA measurement. We have chosen the 8-position test to minimize the possibility of obtaining false positives. We used several C Landolt charts to exclude a learning effect during the VA assessment.

To evaluate VA under different wavelengths we illuminated the chart sequentially with white (W), green (G), red (R) and blue (B) LEDs (Thorlabs, Inc., USA) with spectral data detailed in Table 1.

\begin{tabular}{clccc}
\hline Light & Manufacture model & $\lambda(\mathrm{nm})$ & FWHM $(\mathrm{nm})$ & CCT(K) \\
\hline W & Thorlabs MCWHL5-LED & - & - & 6500 \\
G & Thorlabs M530L3-LED & 530 & 33 & - \\
R & Thorlabs M625L3-LED & 625 & 18 & - \\
B & Thorlabs M455L3-LED & 455 & 18 & - \\
\hline
\end{tabular}

Table 1. Spectral data of LEDs ${ }^{\mathrm{a}} \cdot{ }^{\mathrm{a}}$ Nominal data from Thorlabs[26], $\lambda=$ peak wavelength, FWHM=Full Width at Half Maximum,CCT=Correlated Colour Temperature

\section{2.b. Method}

Informed consent was obtained from all participants, following an explanation of the study examinations in accordance with the tenets of the Declaration of Helsinki. Ethical approval was obtained from the Ethical Committee of the Hospital de Mataró (Consorci Sanitari del Maresme, Barcelona, Spain).

All subjects' examinations in both groups were carried out by an experienced optometrist (LC). Retinoscopy and subjective refraction at $3.5 \mathrm{~m}$ using a trial frame and a standard spectacle trial lens set was performed 
in both groups so, the vergence of $0.25 \mathrm{D}$ of measuring $\mathrm{VA}$ at $3.5 \mathrm{~m}$ was included in the manifest refraction. The refractive correction ( $\mathrm{Rx}$ ) obtained under white illumination was used in all the tests performed subsequently. All VA measurements were taken monocularly. The eye chosen for the trial was the one that showed better VA for white light (W-VA) and under natural pupil.

The optotype chart was illuminated successively with each R, G, B LED to test the respective R-VA, G-VA and $B-V A$. The order of the LED presentation was randomized, and subjects were only prompted once for each VA measure. The value registered for VA corresponded to the last visual level where the patient recognized the 5 stimuli; however, when some stimuli of the next level were further identified, the resulting VA was annotated by subtracting 0.02 LogMAR units for each additional stimulus correctly recognised.[27] Measurements for all subjects were taken under the same conditions of illumination.

The chart was placed at $3.5 \mathrm{~m}$ from the subject to assess distance VA in both groups. Only for the phakic group, near VA was measured under free accommodation by adding a -3.00D lens to simulate a vergence of $33 \mathrm{~cm}$. To ensure that the accommodation was preserved in all the young phakic subjects, monocular accommodative facility in near distance (with \pm 2.00 D lenses) was previously tested.

\section{2.c. Observers}

We recruited 61 participants: 31 young phakic observers and 30 pseudophakic patients implanted with a monofocal IOL.

Participants from the phakic group were students from the Faculty of Optics and Optometry of the Universitat Politècnica de Catalunya, in Terrassa (Barcelona). The inclusion criteria were: VA with Rx better than 0.1 logMAR (Snellen 6/7.5), refractive error (spherical equivalent) less than $\pm 5,00 \mathrm{D}$ and accommodation preserved. The presence of any ocular pathology and abnormalities in colour vision or accommodation disorders were grounds for exclusion.

The pseudophakic group were patients from the Hospital de Mataró (Consorci Sanitari del Maresme, Barcelona) after undergoing cataract surgery. All patients were implanted with a monofocal IOL (Y601075, AJL Ophthalmic, Spain) (Table 2).

\begin{tabular}{lc}
\hline Manufacturer and model & AJL Ophthalmic. Y601075 \\
Material & Hydrophilic acrylate \\
Optical/Total diameter $(\mathrm{mm})$ & $6.0 / 10.75$ \\
Refractive index (n) & 1.46 \\
Abbe value & 47 \\
Design & Spheric monofocal \\
Color filter & UV-blocking \\
\hline
\end{tabular}

Table 2. IOL features[28].

The surgery was performed between one and three months before the examination. The inclusion criteria were: patients undergoing cataract surgery using the phacoemulsification technique with monofocal intraocular lens implant, post-surgical VA with refractive correction $(\mathrm{Rx})$ better than 0.1 logMAR (Snellen $6 / 7.5$ ), prior refractive error (spherical equivalent) less than $\pm 5.00 \mathrm{D}$. Key exclusion criteria were: abnormal colour vision, complications during or post-surgery and prior ocular pathology or ocular surgery. Table 3 shows demographic and clinical characteristics of the participants.

\begin{tabular}{lcc}
\hline & Phakic & Pseudophakic \\
\hline Number of eyes & 31 & 30 \\
Age (years) & $23.06[\mathrm{SD}=5.11]$ & $68.64[\mathrm{SD}=9.52]$ \\
& $(18$ to 35$)$ & $(42$ to 82$)$ \\
Spherical equivalent at & $-1.08[\mathrm{SD}=2.2]$ & $-0.05[\mathrm{SD}=0.56]$ \\
$3.5 \mathrm{~m}$ (D) & $(-4.5$ to +4.5$)$ & $(-1.25$ to +1.25$)$ \\
W-VA at 3.5m(logMAR) & $-0.104[\mathrm{SD}=0.06]$ & $-0.012[\mathrm{SD}=0.07]$ \\
(Snellen) & $(6 / 4.74)$ & $(6 / 5.82)$ \\
IOL optical power (D) & & $19.91[\mathrm{SD}=2.82]$ \\
& & $(15$ to 26$)$ \\
\hline
\end{tabular}

Table 3. Descriptive data of the subjects (mean [SD]) 


\section{2.d. Statistical analysis}

Statistical analysis was performed using SPSS software version 13.0 (SPSS Inc, Chicago, IL). Descriptive statistics (mean [standard deviation (SD)]) were used to characterize the sample. Significance of differences among VA corresponding to different lights was tested with a repeated measures analysis of variance for each group. T-test was used to assess significance of VA differences between groups. Data sphericity was assessed with Mauchly's tests. Normality of residuals followed from Kolmogorov-Smirnov tests for every fitted model. P-values under 0.05 were considered statistically significant.

\section{Results}

We measured distance VA under R, G, B and W illumination in phakic and pseudophakic eyes using the procedure described in section 2. Table 4 and Figure 1 show the mean VA and standard desviation (SD) values for each colour in the two groups:

\begin{tabular}{cccccc} 
Number of eyes & Group & White-VA & Red-VA & Green-VA & Blue-VA \\
\hline 31 & phakic & $-0.104[\mathrm{SD}=0.06]$ & $-0.108[\mathrm{SD}=0.08]$ & $-0.054[\mathrm{SD}=0.12]$ & $0.258[\mathrm{SD}=0.16]$ \\
& & $(6 / 4.74)$ & $(6 / 4.68)$ & $(6 / 5.34)$ & $(6 / 10.86)$ \\
30 & pseudophakic & $-0.012[\mathrm{SD}=0.07]$ & $0.045[\mathrm{SD}=0.08]$ & $-0.009[\mathrm{SD}=0.08]$ & $0.258[\mathrm{SD}=0.06]$ \\
& & $(6 / 5.82)$ & $(6 / 6.66)$ & $(6 / 5.88)$ & $(6 / 10.86)$ \\
\hline
\end{tabular}

Table 4: Mean distance VA values (logMAR) and [SD] under R, G, B and W illumination. Values in Snellen notation are given in brackets

(a)

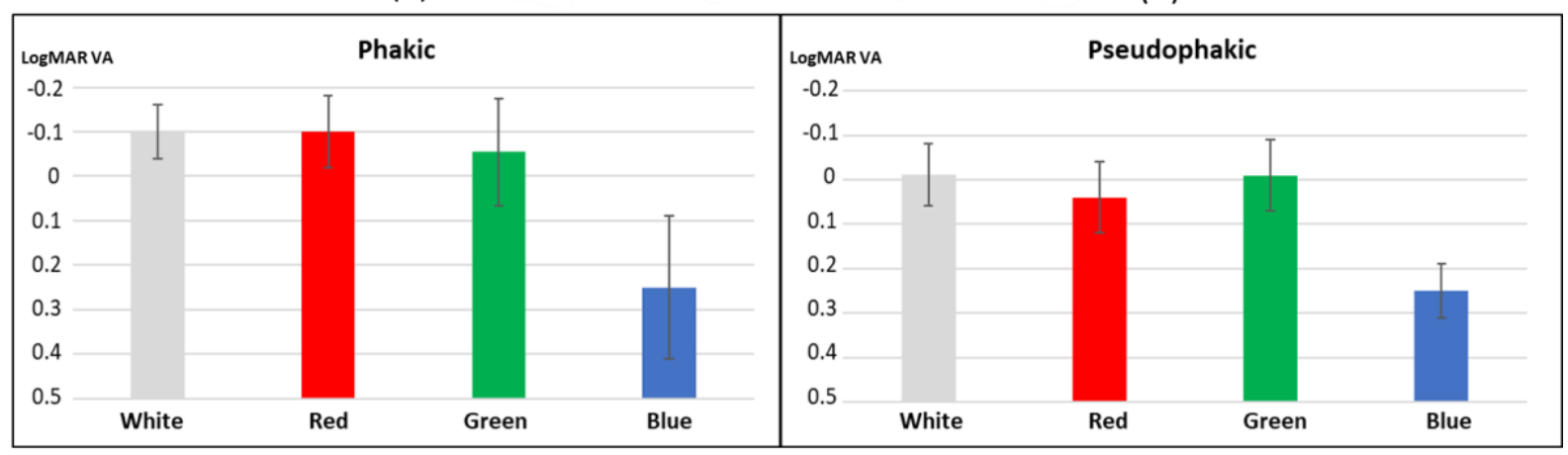

Figure 1. Distance VA under white, red, green, and blue light (mean, SD): (a) phakic group, (b) pseudophakic group.

In Figure 1 (a) and Table 4 (first row) we observe the mean distance VA obtained with each light for the phakic group. The highest levels of the mean distance VA were reached with white and red lights, which showed close values $(\mathrm{W}-\mathrm{VA}=-0.104$ and $\mathrm{R}-\mathrm{VA}=-0.108)$. In comparison to them, the mean distance VA under green light (G-VA=-0.054) was slightly lower.

Figure 1 (b) and Table 4 (second row) show the mean distance VA values for the pseudophakic group under $\mathrm{R}, \mathrm{G}$ and $\mathrm{B}$ illumination. In this case, the best distance VA corresponded to the white and green illuminations, with remarkably close mean values $(\mathrm{W}-\mathrm{VA}=-0.012$ and $\mathrm{G}-\mathrm{VA}=-0.009)$. The mean distance VA under red illumination ( $\mathrm{R}-\mathrm{VA}=0.045)$ was, in turn, slightly worse.

Comparing both the phakic and the pseudophakic groups (Figures 1 (a) and 1 (b)), the mean distance VA assessed under W light (W-VA) was significantly higher in the phakic group as it could be expected $(\mathrm{p}<0.01)$. Certainly, the phakic group was much younger $(23.06[\mathrm{SD}=5.11])$ than the pseudophakic $(68.64$ [SD=9.52]) and it is known that VA tends to decline with age.[29], [30] No difference was observed, however, with blue light (phakic=0.258 $[\mathrm{SD}=0.16](6 / 10.86)$, pseudophakic=0.258 $[\mathrm{SD}=0.06](6 / 10.86) \mathrm{p}=0.9)$. The mean distance VA under blue light (B-VA) was the worst for both groups.

The effect of the colour lighting on VA within each group - phakic and pseudo-phakic - was our primary goal. Its significance was assessed with a repeated measures analysis of variance. The sphericity assumption 
failed for both groups. Therefore, degrees of freedom were consequently corrected following GreenhouseGeisser correction. A significant effect of the colour lighting on the distance VA was found in each group

(phakic, $p$-value $<0.0005$; pseudophakic, $p$ value $<0.0005$ ). In the phakic group, pairwise comparisons among colours show that the mean distance VA differed significantly for all pairs, except for red and white illuminations (Table 5).

\begin{tabular}{llll}
\hline Phakic & blue & green & red \\
\hline green & p-value $<0.001$ & & \\
red & p-value $<0.001$ & p-value $=0.032$ & \\
white & p-value $<0.001$ & p-value $=0.019$ & p-value $>0.999$ \\
\hline
\end{tabular}

Table 5: VA pairwise comparisons among colour illuminations. Phakic group. Distance vision

In the pseudophakic group, there are also significant differences between each pair of colours, except for green and white illuminations (Table 6).

\begin{tabular}{llll}
\hline Pseudophakic & blue & green & red \\
\hline green & p-value $<0.001$ & & \\
red & p-value $<0.001$ & p-value $<0.001$ & \\
white & p-value $<0.001$ & p-value $>0.999$ & p-value $<0.001$ \\
\hline
\end{tabular}

Table 6: VA pairwise comparisons among colour illuminations. Pseudophakic group

Figure 2 represents Bonferroni confidence intervals (CI) for the mean differences of distance R-VA, G-VA and B-VA taking as a control the distance W-VA for the phakic and pseudophakic groups.

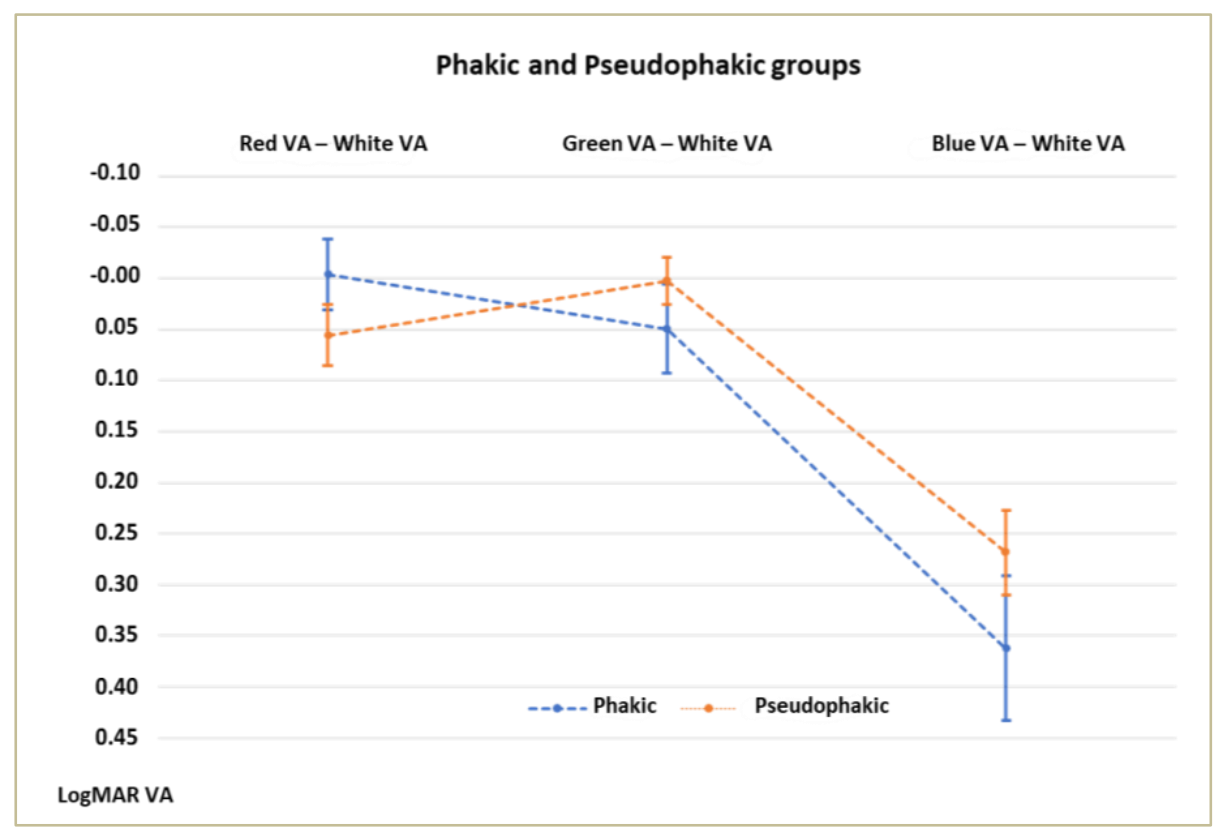

Figure 2: Bonferroni 95\% CI for mean differences of distance VA under either R, G, B illumination with respect to white lighting

Although the mean distance R-VA and G-VA were higher, in general terms, for the young phakic eyes than for the elderly pseudophakics, we remark a different behaviour between both groups with respect to their intragroup mean distance W-VA. While the young phakics are able to reach significantly equal VA under either R and W illumination, but significantly lower under G light, the opposite happens with the elderly pseudophakics, who are able to reach significantly equal VA under either G and W illumination, but significantly lower under R light. 
We analysed the results of the young phakic group in near vision conditions. The mean near VA values obtained with a -3.00D lens for the phakic group are displayed in Figure 3 and Table 7.

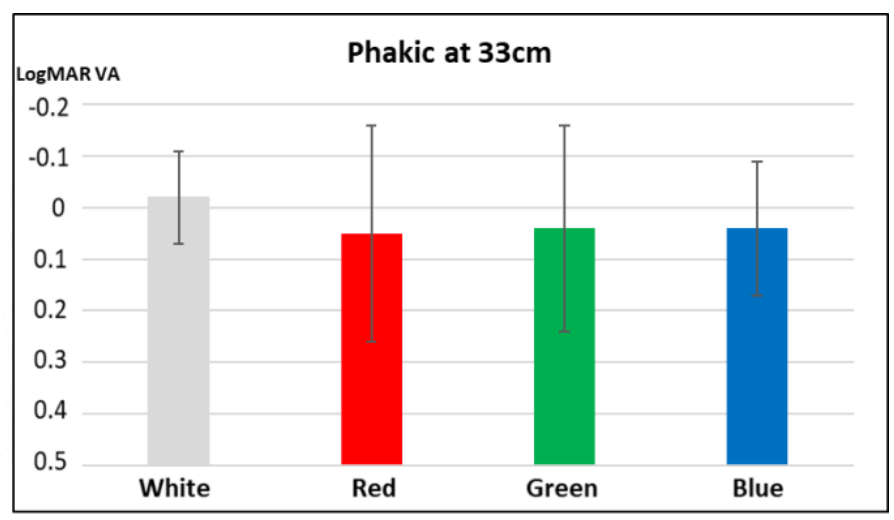

Figure 3: Phakic group near VA under white, red, green and blue light (mean, SD)

\begin{tabular}{cccccc}
\hline Number of eyes & Group & W-VA & R-VA & G-VA & B-VA \\
\hline 31 & phakic-near & $-0.027[\mathrm{SD}=0.09]$ & $0.05[\mathrm{SD}=0.21]$ & $0.04[\mathrm{SD}=0.20]$ & $0.04[\mathrm{SD}=0.13]$ \\
& & $(6 / 5.64)$ & $(6 / 6.72)$ & $(6 / 6.6)$ & $(6 / 6.72)$ \\
\hline
\end{tabular}

Table 7: Near VA values of the phakic group under R, G, B and W illumination (mean [SD]). Values in Snellen notation are given in brackets

Table 8 shows statistically significant difference between the mean VA measured under white and under blue illumination but no statistically significant difference among the near VA corresponding to the R, G, B colour lights. In this case, the results reveal a balanced accommodation capability to each wavelength, but with a significantly lower VA than under W light. Yet, a high variability is observed, particularly in the near VA assessment under $\mathrm{R}$ and $\mathrm{G}$ lights.

\begin{tabular}{llll}
\hline Phakic-near & blue & green & red \\
\hline green & $\mathrm{p}$-value $>0.999$ & & \\
red & p-value $>0.999$ & p-value $>0.999$ & \\
white & p-value $=0.015$ & p-value $=0.175$ & p-value $=0.133$ \\
\hline
\end{tabular}

Table 8: VA pairwise comparisons among colour illuminations. Phakic-near group

\section{Discussion}

LCA of the eye has been widely studied using different techniques and numerous studies report experimental measurements of CDRx, but few works consider the LCA impact on vision through a subjective quality metrics of visual performance, broadly used in clinical practice, such as VA. We assessed the VA under quasi-monochromatic illumination with different R, G, B wavelengths, and compared them with VA outcomes under white light. To our knowledge, this is the first study that uses R, G, B as well as W lights to assess intraclass and interclass VA changes in young phakic and elderly pseudophakic eyes.

The results depicted in Figure 1 show that, beyond age-related decline, the differences between distance VAs under colour and white illumination are not the same for young phakic and pseudophakic eye groups. Although the interclass differences might be considered subtle, a further analysis of variance on repeated measures (within-subject) has allowed us to demonstrate its statistical significance.

For the phakic group (Figure 1 (a)), the best distance VA is obtained under R light (R-VA) which is quite similar to $\mathrm{W}$-VA. The G illumination gives slightly lower G-VA values than R-VA and the lowest values were those obtained with B light (B-VA). We can explain our results taking into account those reported by Vinas et al.[4] in figure $7 \mathrm{a}$ in their paper, where CDRx values obtained from psychophysical measurements of various studies appear plotted versus wavelength (with $\mathrm{CDRx}=0$ set to $555 \mathrm{~nm}$ ). In that figure, for the wavelength of $625 \mathrm{~nm}$, the CDRx value is around $+0,40 \mathrm{D}$ approximately, which corresponds to mild 
hypermetropia. In our work, young phakic observers with accommodation preserved were able to compensate such hypermetropia with accommodation, and so, they reached under red illumination the high distance VA (-0.1 logMAR)(Snellen=6/4.68) already reached under white light. Note that they were not able to further improve the latter distance VA outcomes, even though chromatic aberration does blur the retinal image formed with white light as opposite to what happens with quasi-monochromatic illumination. For $530 \mathrm{~nm}$ the point in focus value corresponds to a slightly negative CDRx (between 0 and $-0.25 \mathrm{D}$ ) in Fig 7a of Ref 4. This somewhat myopic condition also agrees with the distance VA obtained in our work for the green wavelength (G-VA=-0.054 logMAR (Snellen 6/5.34)), which is slightly worse than the distance VA obtained with red light, (R-VA=-0.0108 logMAR (Snellen 6/4.68)). For the blue wavelength $(455 \mathrm{~nm})$, Vinas et al. reported a point in focus of CDRx around -0.8D which correspond to further myopia. This result is also in very good agreement with the relatively poor distance B-VA=0.26 logMAR (Snellen 6/10.86) obtained in our work. Taking into account that a refractive error of $-0.75 \mathrm{D}$ would correspond to an approximate VA of 0.30LogMAR (Snellen 6/12)[31] we can state that our results approximated the value of distance VA to those CDRx measures obtained in previous studies. Our distance VA results are in good agreement with a referral wavelength in focus of $555 \mathrm{~nm}$, as reported by Vinas et al.,[4] but there is a marked variability in the wavelength in focus reported in other studies. Thus, for instance, Cooper and Pease[10] reported $518 \mathrm{~nm}$ and Jenkins[32] 596nm. Note that the wavelength in focus considered by Vinas et al. is in the midpoint of this range.

Figure 1(b) shows the distance VA results obtained for the pseudophakic group. Here, the highest VA was reached with W light (very close to the G-VA). This result differs from the young phakic group, for which the $\mathrm{R}$-VA better approximated the W-VA.

The effects of the implanted IOL are on the basis of a possible explanation for these results. On the one hand, the design wavelength of IOLs corresponds to a green light, as fixed by the ISO standard [33] to 546nm and therefore, is commonly taken as a reference to target the IOL power before surgery. On the other hand, the IOL material and design may further introduce a LCA change in the pseudophakic eye. Even though the pseudophakic eye still showed LCA and was somewhat hypermetropic under R illumination, which appears to be the case in Fig. 1(b), by no means the pseudophakic eye would be able to compensate for such ametropia because of the loss of accommodation after a monofocal implant. VA outcomes would likely change if using IOLs with different characteristics. Thus, for an IOL design with reduced LCA or, much better, ideally intended to compensate for corneal LCA, some improvement in the VA outcomes of pseudophakic subjects would be reasonably expectable, at least under B light.

Figure 3 shows the near VA results obtained after adding a $-3.00 \mathrm{D}$ lens to force near distance accommodation in young phakic eyes. There is no significant difference between the mean VA values measured in these conditions under R, G, B lights (Table 8). We can explain these results taking into account that accommodation varies to compensate for LCA. With short wavelength illumination, the eye underaccommodate. The opposite happens with long wavelength illumination, since the eye has to overaccommodate to focus the image clear onto the retina. This result is consistent with those reported by other studies.[6], [10] However, near VA measurements show high fluctuations when monochromatic light is used. In our work, we appreciated the difficulty of some observers to focus on near vision with monochromatic light, particularly red and green. This might be due to the decreased accommodative response when monochromatic light is used.[11], [12], [34]

Interestingly, the near VA under separate R, G, B lights, which allowed the young phakic subject to have sharper retinal images, were not higher than the near VA under white light, which actually produced retinal images with chromatic blur. This result agrees with Campbell et al.[22] who reported that monochromatic illumination did not improve contrast sensitivity and VA with respect to white light for $4 \mathrm{~mm}$ pupil size.

\section{Conclusion}

In this work, we have measured VA under monochromatic light in phakic and pseudophakic eyes and the results obtained are consistent with those of CDRx reported by other researchers. Changes from phakic to pseudophakic distance VA results have been explained from the lack of accommodation of pseudophakic eyes and IOL power calculations, which commonly use a green design wavelength to target the desired postoperative refraction, amidst other factors such as the dispersive properties of the IOL material and ageing. 
Further research with different IOL materials and designs (monofocal, multifocal) should be performed for a better understanding and insight of the interaction of the IOL optical properties on VA.

\section{Acknowledgements}

This work was supported by the Spanish Ministerio de Economía y Competitividad and FEDER funds under project Ref. DPI2016-76019-R. 